\title{
Hipoksia Jaringan dan Kadar Laktat pada Leukemia Limfoblastik Akut dengan Demam Neutropenia dalam Fase Induksi
}

\author{
Nusarintowati Ramadhina, Endang Windiastuti, H.I.Budiman \\ Departemen Ilmu Kesehatan Anak FKUI Rumah Sakit Dr. Cipto Mangunkusumo, Jakarta
}

\begin{abstract}
Latar belakang. Pada Leukemia limfoblastik akut (LLA), proses fagositosis oleh neutrofil kurang atau tidak efektif (kondisi neutropenia) memungkinkan bertahannya bakteri yang tidak dapat didigesti, sehingga timbul proses inflamasi yang selanjutnya dapat menimbulkan gangguan mikrosirkulasi.

Tujuan. Mengetahui gangguan mikrosirkulasi pada pasien LLA dengan demam neutropenia dalam fase induksi dengan menggunakan 2 parameter yaitu kadar oksigen darah vena ( $\mathrm{SvO} 2)$ dan kadar laktat darah.

Metode. Penelitian potong lintang, Maret 2007-Maret 2008 pada pasien LLA berusia 0-18 tahun. Pengambilan sampel secara consecutive sampling, pada pasien LLA baru yang mendapat terapi sitostatika dalam fase induksi dengan jumlah absolut neutrofil $<1000 / \mathrm{uL}$ dan terdapat satu kali episode demam.

Hasil. Lima belas dari 49 subjek (31\%) memiliki kadar oksigen darah vena di bawah 60\%. Rerata SvO2 64,11 $\pm 9,24 \%$, pada neutropenia berat rerata $\mathrm{SvO} 2$ lebih rendah dibandingkan pada neutropenia sedang $(56,78 \pm 7,99 \%$ vs. $69,16 \pm 6,18 \%$ ). Tidak tampak hubungan antara beratnya neutropenia dengan kadar SvO2. Pada pemeriksaan kadar laktat, 38 dari 49 subjek (78\%) memiliki kadar laktat di atas 2 mmol/L. Rerata kadar laktat darah 3,04 $\pm 1,14$ $\mathrm{mmol} / \mathrm{L}$, pada neutropenia berat rerata kadar laktat darah lebih tinggi dibandingkan neutropenia sedang $(3,52 \pm 1,33$ $\mathrm{mmol} / \mathrm{L}$ vs. $2,72 \pm 0,87 \mathrm{mmol} / \mathrm{L})$. Beratnya neutropenia mempengaruhi kadar laktat darah, 15 subjek dengan $\mathrm{SvO} 2$ $<60 \%, 13$ subjek (87\%) mengalami pula peningkatan kadar laktat darah di atas 2 mmol/L, 27 dari 34 subjek (79\%) memiliki kadar laktat darah lebih dari 2 mmol/L meskipun kadar SvO2 dalam batas normal.

Kesimpulan. Pada pasien LLA dengan demam neutropenia, kadar neutropenia mempengaruhi kadar laktat darah namun tidak mempengaruhi kadar SvO2 sehingga hasil kadar laktat lebih dapat digunakan dengan segera untuk menunjukkan gangguan mikrosirkulasi dibandingkan hasil SvO2. (Sari Pediatri 2008;10(3):158-62).
\end{abstract}

Kata kunci: Leukemia limfoblastik akut, neutropenia, mikrosirkulasi, laktat darah, saturasi oksigen darah vena.

\footnotetext{
Alamat Korespondensi:

Dr. Nusarintowati Ramadhina, SpA. Departemen Ilmu Kesehatan Anak, Fakultas Kedokteran Universitas Indonesia/ Rumah Sakit Cipto Mangunkusumo Jl. Salemba Raya N0. 6, Jakarta 10430, Indonesia Tel : +62-21-3919016 E-mail : drnuviubay@yahoo.com
}

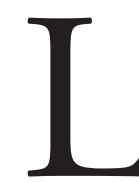

eukemia limfoblastik akut merupakan jenis leukemia tersering pada anak dan angka kejadian di negara berkembang mencapai 83\% dari seluruh leukemia. ${ }^{1,2}$ Pasien leukemia memerlukan keadaan optimal untuk mendapatkan 
terapi kuratifnya dan salah satu keadaan yang perlu diperhatikan adalah neutropenia karena peran sel neutrofil dalam mencegah dan melawan infeksi melalui mekanisme fagositosis. Keadaan neutropenia pada LLA dapat terjadi akibat desakan oleh sel leukemia atau terapi sitostatika dan dapat terjadi tanpa gejala klinis infeksi yang nyata. ${ }^{1,2}$ Neutropenia yang disertai demam dengan suhu tubuh di atas $38^{\circ} \mathrm{C}$ selama 2 jam atau $39^{\circ} \mathrm{C}$ dalam sekali pengukuran, memiliki potensi infeksi lebih tinggi dan 34\% di antaranya dapat mengalami komplikasi serius yang mengancam jiwa. ${ }^{1,2}$

Infeksi berat diukur secara makrovaskular dengan mengukur parameter hemodinamik global seperti tekanan darah. Trzeciak ${ }^{3}$ mengungkapkan bahwa sebelum terjadi gangguan makrovaskular telah terjadi proses lain yang tersembunyi, yaitu gangguan mikrosirkulasi seperti hipoksia jaringan yang luas, kerusakan sel endotel, aktivasi kaskade koagulasi dan microcirculatory and mitochondrial distress syndrome. Faktor-faktor tersebut merupakan hal yang penting dalam menentukan potensi ke arah sepsis namun keadaan ini tidak terdeteksi secara klinis sehingga keadaan pasien seolah-olah stabil. Proses fagositosis oleh neutrofil yang kurang atau tidak efektif pada kondisi neutropenia memungkinkan bertahannya bakteri yang tidak dapat dicerna sehingga timbul proses inflamasi yang selanjutnya dapat menimbulkan gangguan mikrosirkulasi.

Parameter yang dapat dipergunakan untuk menilai terjadinya gangguan mikrosirkulasi antara lain adalah peningkatan kadar laktat darah dan secara cepat dapat memberi gambaran hipoperfusi atau hipoksia jaringan. Kadar laktat darah lebih dari $2 \mathrm{mmol} / \mathrm{L}$ disebut hiperlaktatemia menunjukkan adanya inadekuasi perfusi jaringan. ${ }^{3}$ Parameter oksigenisasi jaringan dapat pula diukur dengan kadar oksigen darah vena atau mixed venous oxygen $(\mathrm{SvO} 2)$ dengan nilai normal 60\%-80\%. Kadar SvO2 di bawah 60\% merupakan parameter yang menunjukkan bahwa venular ends kapiler terdiri atas darah deoksigenisasi. ${ }^{3,4}$

Penelitian ini bertujuan untuk melihat gangguan mikrosirkulasi pada pasien LLA dengan demam neutropenia setelah fase induksi dengan menggunakan 2 parameter yaitu kadar $\mathrm{SvO} 2$ dan kadar laktat darah.

\section{Metode}

Penelitian potong lintang dilakukan bulan Maret 2007-Maret 2008 pada semua subjek pasien LLA berusia 0-18 tahun yang telah didiagnosis dengan pemeriksaan aspirasi sumsum tulang. Pasien dirawat di bangsal perawatan Departemen Ilmu Kesehatan Anak FKUI-RS Dr. Cipto Mangunkusumo Jakarta. Cara pengambilan sampel berurutan sesuai waktu masuk rumah sakit (consecutive sampling). Kriteria inklusi subjek adalah pasien baru LLA, mendapat terapi sitostatika fase induksi, mempunyai jumlah absolut neutrofil $<1000 / \mu \mathrm{L}$, dan mengalami satu kali episode demam.

Jumlah absolut neutrofil (JAN) yaitu jumlah sel neutrofil batang dan segmen dibagi 100 kemudian dikalikan jumlah leukosit. ${ }^{1}$ Neutropenia bila JAN di bawah $1000 / \mu \mathrm{L}$, neutropenia sedang bila JAN 500$1000 / \mu \mathrm{L}$ sedangkan neutropenia berat bila JAN di bawah $500 / \mu \mathrm{L}$. Batasan demam apabila suhu aksila di atas $38^{\circ} \mathrm{C}$ yang menetap lebih dari 2 jam atau suhu di atas $39^{\circ} \mathrm{C}$ pada satu kali pengukuran. ${ }^{5}$ Terhadap anak yang memenuhi kriteria inklusi dimintakan ijin turut dalam penelitian dari orangtua, dengan menandatangani surat persetujuan penelitian. Diambil darah tepi untuk pemeriksaan kadar saturasi darah vena dan kadar laktat darah. Kadar laktat darah meningkat bila berada di atas $2 \mathrm{mmol} / \mathrm{L}$, namun pada keadaan sepsis dapat berada di atas $4 \mathrm{mmol} / \mathrm{L} .{ }^{3}$ Kadar oksigen darah vena dianggap rendah bila berada di bawah $60 \% .^{3}$

Semua data klinis dan hasil laboratorium dicatat dalam status penelitian. Data diolah dengan menggunakan program SPSS versi 14.0. Data deskriptif akan disajikan dalam bentuk narasi dan tabel.

\section{Hasil}

Selama periode penelitian terdapat 69 pasien LLA yang dirawat di Departemen Ilmu Kesehatan Anak FKUIRS Dr Cipto Mangunkusumo dan 49 di antaranya memenuhi kriteria inklusi.

Tabel 1 memperlihatkan usia subjek termuda adalah 1 tahun sedangkan yang tertua berusia 15 tahun dengan median pada usia 4 tahun. Status gizi dinilai dengan pengukuran lingkar lengan atas, didapatkan sebagian besar pasien berada pada gizi kurang dan hanya 3 subjek secara antropometri dan klinis masuk dalam gizi baik. Pada penelitian ini terdapat 20 subjek dengan neutropenia berat dan 29 subjek dengan neutropenia sedang.

Tabel 2 tertera keadaan demam neutropenia terdapat pada 15/49 subjek penelitian, kadar SvO2 di bawah 
Tabel 1. Sebaran karakteristik subjek penelitian

\begin{tabular}{llcc}
\hline \multicolumn{1}{c}{ Karakteristik } & & $\mathrm{n}$ & $\%$ \\
\hline Jenis kelamin & Laki-laki & 30 & 61 \\
& Perempuan & 19 & 39 \\
Usia (tahun) & $<2$ & 2 & 4 \\
& $2-5$ & 32 & 65 \\
Status gizi & $>5$ & 15 & 31 \\
& Kurang & 46 & 94 \\
Aspirasi sumsum tulang & Baik & 3 & 6 \\
& L1 & 36 & 74 \\
& L2 & 7 & 14 \\
Demam (oC) & L3 & 6 & 12 \\
Jumlah absolut neutrofil $(\mu \mathrm{L})$ & $<500 /$ & 41 & 84 \\
& $38-<40$ & 8 & 16 \\
& 40 & 41 \\
& & 29 & 59 \\
\hline
\end{tabular}

Tabel 2. Sebaran SvO2 darah terhadap pasien LLA menurut beratnya neutropenia

\begin{tabular}{cccc}
\hline $\begin{array}{c}\text { Jumlah absolute } \\
\text { neutrofil }(\mu \mathrm{L})\end{array}$ & \multicolumn{3}{c}{ Kadar SvO2 (\%) } \\
\cline { 2 - 4 } & $<60$ & $\geq 60$ & Jumlah \\
\hline$<500$ & 15 & 5 & 20 \\
$500-1000$ & 0 & 29 & 29 \\
\hline Jumlah & 15 & 34 & 49 \\
\hline
\end{tabular}

$L L A=$ Leukemia limfoblastik akut, $\mathrm{SvO} 2=$ kadar oksigen dalam darah vena, JAN=jumlah absolut neutrofil

$60 \%$ dan merupakan $75 \%$ pada subjek dengan neutropenia berat, dan semua subjek dengan neutropenia sedang mempunyai kadar $\mathrm{SvO} 2 \geq 60 \%$. Rerata kadar $\mathrm{SvO} 2$ pada LLA dengan neutropenia berat $56,78 \%$ $(\mathrm{SD} \pm 7,99 \%)$ lebih rendah daripada subjek dengan neutropenia sedang $69,16 \%(S D \pm 6,18 \%)$. Pemeriksaan kadar laktat darah meningkat di atas $2 \mathrm{mmol} / \mathrm{L}$ pada 38 dari 49 subjek penelitian (78\%).

Tujuh belas diantara 20, 6 subjek neutropenia berat mengalami peningkatan kadar laktat darah dan 6 subjek meningkat di atas $4 \mathrm{mmol} / \mathrm{L}$. Pada neutropenia sedang, 21/29 subjek mengalami peningkatan kadar laktat darah dan 2/29 subjek di antaranya meningkat hingga di atas $4 \mathrm{mmol} / \mathrm{L}$. Rerata kadar laktat darah pada LLA (Tabel 3) dengan demam neutropenia berat $(3,52 \pm 1,33) \mathrm{mmol} / \mathrm{L}$ lebih tinggi dibandingkan dengan neutropenia sedang $(2,72 \pm 0,87) \mathrm{mmol} / \mathrm{L}$.

Tabel berikut memperlihatkan hasil kedua parameter gangguan mikrosirkulasi pada LLA dengan demam neutropenia.
Tabel 3. Kadar laktat pada pasien LLA menurut derajat neutropenia

\begin{tabular}{ccccc}
\hline Jumlah absolut & \multicolumn{4}{c}{ Kadar laktat $(\mathrm{mmol} / \mathrm{L})$} \\
\cline { 2 - 5 } neutrofil $(\mu \mathrm{L})$ & $\leq 2,0$ & $2,1-4,0$ & $>4,0$ & Jumlah \\
\hline$<500$ & 3 & 11 & 6 & 20 \\
$500-1000$ & 8 & 19 & 2 & 29 \\
\hline Jumlah & 11 & 30 & 8 & 49 \\
\hline LLA=Leukemia limfoblastik akut, JAN=jumlah absolut neutrofil
\end{tabular}

Tabel 4. Kadar oksigen darah vena dan laktat darah pada LLA dengan demam neutropenia

\begin{tabular}{cccc}
\hline \multirow{2}{*}{ SvO2 $(\%)$} & \multicolumn{3}{c}{ Kadar Laktat darah $(\mathrm{mmol} / \mathrm{L})$} \\
\cline { 2 - 4 } & $\leq 2,0$ & $>2$ & Jumlah \\
\hline$<60$ & 2 & 13 & 15 \\
$\geq 60$ & 7 & 27 & 34 \\
Range SvO2 & $52,4-77,9$ & $44,3-76,9$ & \\
Rerata \pm SD & $64,90 \pm 8,82$ & $61,90 \pm 10,38$ & \\
\hline
\end{tabular}

LLA=Leukemia Limfoblastik Akut, SvO2=kadar oksigen dalam darah vena

Tiga belas dari 15 subjek memiliki kadar $\mathrm{SvO} 2$ di bawah 60\%, mengalami pula peningkatan kadar laktat darah di atas $2 \mathrm{mmol} / \mathrm{L}$. Diantara 34 subjek 27 memiliki kadar laktat darah lebih dari 2 $\mathrm{mmol} / \mathrm{L}$ meskipun kadar $\mathrm{SvO} 2$ dalam batas normal $\geq 60 \%$. Range SvO2 untuk kadar laktat normal $(52,4-77,9) \%$ dengan rerata $64,90 \%(\mathrm{SD} \pm 8,82 \%)$ sedangkan bila kadar laktat di atas $2 \mathrm{mmol} / \mathrm{L}$ maka range $\mathrm{SvO} 244,3-76,9 \%$ dengan rerata $61,90 \%$ $(\mathrm{SD} \pm 10,38 \%)$.

Pada Gambar 1 tertera diagram sebar kadar $\mathrm{SvO} 2$ menurut derajat neutropenia. Sebaran $\mathrm{SvO} 2$ pada subjek dengan neutropenia berat lebih banyak berada di bawah nilai normal dibandingkan subjek dengan neutropenia sedang. Kadar $\mathrm{SvO} 2$ tampak tidak memiliki hubungan dengan beratnya neutropenia. Rerata kadar $\mathrm{SvO} 2$ semua subjek pada kisaran normal yaitu $(64,1 \pm 9,2) \%$.

Gambar 2 memperlihatkan diagram sebar kadar laktat darah menurut derajat neutropenia. Sebaran kadar laktat darah pada subjek dengan neutropenia berat lebih banyak berada di atas nilai normal (rerata 3,52 $\pm 1,33 \mathrm{mmol} / \mathrm{L}$ ) dibandingkan subjek dengan neutropenia sedang (rerata 2,72 $\pm 0,87 \mathrm{mmol} / \mathrm{L}$ ). Derajat neutropenia mempengaruhi kadar laktat darah, namun tidak mempengaruhi saturasi oksigen darah vena. 


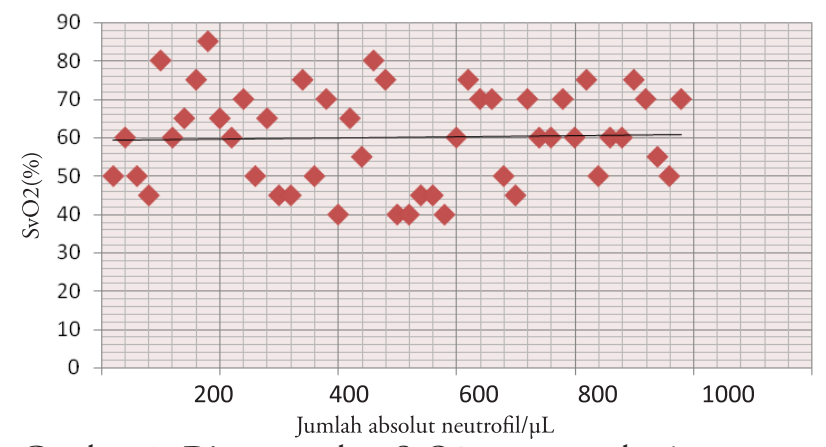

Gambar 1. Diagram sebar SvO2 menurut derajat neutropenia

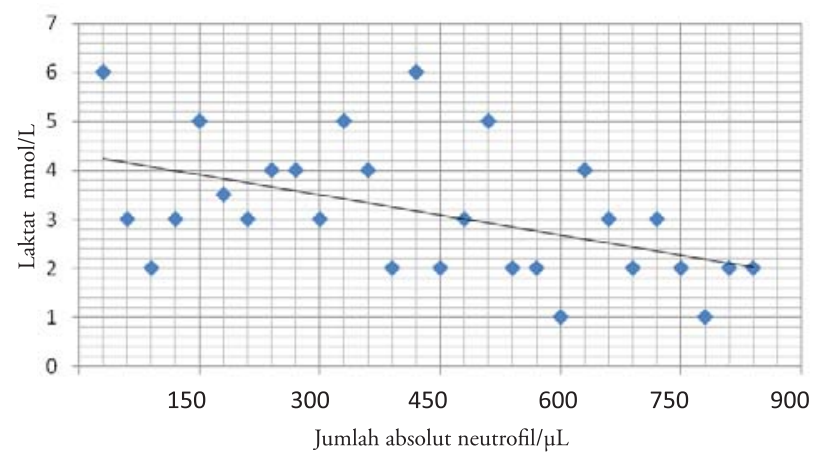

Gambar 2. Diagram sebar kadar laktat darah menurut derajat neutropenia

\section{Diskusi}

Demam merupakan satu-satunya gejala dan tanda kemungkinan proses inflamasi yang berlanjut pada gangguan mikrosirkulasi. Keadaan tersebut diperberat oleh neutropenia mengingat tidak didapatkan fokus infeksi lain secara klinis.

SvO2 menunjukkan bahwa venular ends kapiler terdiri atas darah deoksigenisasi. Konsep ini diperkenalkan dengan model Krogh melalui area silinder yang menunjukkan aliran darah deoksigenasi atau lethal-corner sehingga terjadi hipoksia jaringan di sekitarnya dan metabolisme anaerob. ${ }^{3}$ Pada hipoksia jeringan, kadar $\mathrm{SvO} 2$ turun di bawah 60\%, sebagai kompensasi terjadi mekanisme shunting pada jaringan terhadap kadar SvO2., ${ }^{3,6}$ Oleh karena itu, walaupun kadar SvO2 normal, belum dapat menyingkirkan kemungkinan terjadi hipoksia jaringan. Pada penelitian kami, 15 dari 49 subjek menunjukkan kadar darah vena di bawah $60 \%$, berarti hanya $31 \%$ subjek penelitian yang mengalami hipoksia jaringan. Sedangkan 34 subjek yang memiliki kadar $\mathrm{SvO} 2$ normal belum tentu menunjukkan tidak ada hipoksia jaringan. Berdasarkan laporan Trzeciak ${ }^{3}$ shunting akan mempengaruhi keadaan inadekuasi oksigenisasi pada lethal-corner daerah venul.

Kadar laktat meningkat apabila kadar melebihi $2 \mathrm{mmol} / \mathrm{L}^{7}{ }^{7}$ Trzeciak $^{3}$ dan Rivers ${ }^{8}$ melaporkan bahwa infeksi dengan kadar laktat darah $>4 \mathrm{mmol} / \mathrm{L}$ akan meningkatkan risiko kematian hingga 60,9\% sampai $89 \%$. Kadar normal laktat darah saat istirahat 0,4-1,3 $\mathrm{mmol} / \mathrm{L}$, baik pada pengukuran darah arteri maupun vena, dalam bentuk whole blood maupun plasma. Kadar laktat darah $>2 \mathrm{mmol} / \mathrm{L}$ disebut hiperlaktatemia menunjukkan adanya inadekuasi perfusi jaringan. ${ }^{9-10}$

Tiga puluh delapan diantara 49 subjek menunjukkan kadar laktat darah meningkat lebih dari 2 $\mathrm{mmol} / \mathrm{L}$. Pada keadaan neutropenia berat, 17 dari 20 subjek mengalami peningkatan kadar laktat darah dengan 6 subjek mencapai kadar di atas $4 \mathrm{mmol} / \mathrm{L}$. Pada neutropenia sedang, subjek mengalami peningkatan kadar laktat darah dan hanya 2 subjek mencapai kadar di atas $4 \mathrm{mmol} / \mathrm{L}$. Disimpulkan makin berat derajat neutropenia, makin tinggi kemungkinan peningkatan kadar laktat darah akibat gangguan mikrosirkulasi. Laktat darah memberikan hasil lebih baik sebagai parameter gangguan mikrosirkulasi dibandingkan dengan kadar SvO2. Kadar laktat darah meningkat pada semua subjek dan dipengaruhi berat derajat neutropenia. Pada neutropenia berat, rerata kadar laktat darah $(3,5 \pm 1,3) \mathrm{mmol} / \mathrm{L}$ sedangkan pada neutropenia sedang, rerata kadar laktat darah adalah $(2,7 \pm 0,8) \mathrm{mmol} / \mathrm{L}$.

Rerata kadar SvO2 64,11\% (SD $\pm 9,24)$ sedangkan rerata kadar laktat 3,04 mmol/L $(S D \pm 1,14)$. Pengetahuan mengenai fungsi neutrofil sebagai pertahanan pertama innate immunity sejalan dengan proses inflamasi berlanjut yang dialami pasien neutropenia. Kadar laktat darah sebagai parameter gangguan mikrosirkulasi menunjukkan hasil yang lebih baik dibandingkan pengukuran kadar SvO2. Pada kadar laktat normal range $\mathrm{SvO} 2$ 52,4-77,9\% sedangkan pada kadar laktat darah di atas $2 \mathrm{mmol} / \mathrm{L}$, range $\mathrm{SvO} 2$ lebih rendah $(44,3-76,9 \%)$. Rerata kadar SvO2 pada kadar laktat di atas $2 \mathrm{mmol} / \mathrm{L}$ juga lebih rendah dari rerata kadar $\mathrm{SvO} 2$ pada kadar laktat normal $(61,9 \pm 10,38 \%$ vs. $64,90 \pm 8,82 \%)$. Tampaknya kadar $\mathrm{SvO} 2$, dipengaruhi oleh besarnya shunting dan mekanisme tubuh untuk menyelamatkan daerah yang mengalami inadekuasi oksigenisasi. Kadar laktat darah dapat segera menunjukkan terjadinya gangguan mikrosirkulasi akibat hipoksia jaringan. 
Mendes ${ }^{11}$ mengemukakan protokol untuk mengoptimalkan kondisi pasien keganasan pada anak termasuk LLA terutama dengan demam neutropenia, infeksi, sepsis, syok sepsis, disfungsi organ. Pada pasien LLA dengan demam neutropenia potensi mendapatkan infeksi berat meningkat dengan rasio odds 2,4 (95\%IK 1,3-4,6). ${ }^{11}$ Parameter dini gangguan mikrosirkulasi seperti kadar SvO2, laktat darah, serta kondisi klinis yang mempengaruhi kondisi hemodinamik perlu diketahui untuk menciptakan keadaan optimal pasien LLA yang sedang mendapat terapi statistik. Hasil penelitian kami menunjukkan LLA dengan demam neutropenia telah terjadi gangguan mikrosirkulasi meskipun tanda infeksi secara klinis belum terlihat secara nyata. Namun dengan diketahui adanya gangguan mikrosirkulasi menunjukkan infeksi telah terjadi. Pengetahuan ini akan mempengaruhi prognosis.

Pemberian antibiotik secara empiris menurut Mendes ${ }^{11}$ dapat meminimalkan terjadinya infeksi mengingat pada kasus leukemia disertai neutropenia, dan hanya $10 \%-24 \%$ pembuktian infeksi diperoleh melalui biakan darah yang positif. Pengetahuan mengenai proses sepsis secara dini diperlukan untuk menekan angka mortalitas, mengingat kemungkinan terjadi sepsis pada 12,8\% kasus keganasan terutama leukemia.

\section{Kesimpulan}

Pada LLA dengan demam neutropenia, terdapat penurunan kadar $\mathrm{SvO}_{2}$ (31\%) dan peningkatan kadar laktat darah (78\%). Berat derajat neutropenia mempengaruhi kadar laktat darah namun tidak mempengaruhi kadar $\mathrm{SvO} 2$ sehingga hasil kadar laktat lebih dapat digunakan dengan segera untuk menunjukkan terdapatnya gangguan mikrosirkulasi dibandingkan hasil SvO2. Disarankan pada pasien LLA dengan demam neutropenia perlu diperiksa kadar laktat darah. Pemberian antibiotik dilakukan secara empiris tanpa menunggu hasil kultur darah mengingat proses infeksi telah terjadi pada tingkat mikrosirkulasi. Penelitian lanjutan diperlukan untuk memantau parameter gangguan mikrosirkulasi secara berseri.

\section{Daftar Pustaka}

1. Permono B, Ugrasena IDG. Leukemia akut. Dalam: Permono B, Sutaryo, Ugrasena IDG, Windiastuti E, Abdulsalam M, penyunting. Buku ajar HematologiOnkologi Anak. Edisi ke-1. Jakarta: Balai Penerbit IDAI; 2005. h. 236-47.

2. Gustafsson G, Lie SO. Acute leukaemias. Dalam: Voute PA, Kalifa C, Barrett A, penyunting. Cancer in children clinical management. Edisi ke-4. New York: Oxford University Press; 1998. h. 99-115

3. Trzeciak S, Rivers EP. Clinical manifestations of disorderes microcirculatory perfusion in severe sepsis. Crit Care Med 2005;9: S20-6.

4. Valenza F, Aletti G, Fossali T, Chevallard G, Sacconi F, Irace M, dkk. Lactate as a marker of energy failure in criticaly ill patients: hypothesis. Crit Care 2005,9: 3818-23.

5. Windiastuti E. Antibiotika pada demam neutropenia. Dalam: Tumbelaka AR, Trihono PP, Kurniati N, Widodo DP, penyunting. Penanganan demam pada anak secara profesional. Jakarta: PKB ke-47 Departemen IKA FKUIRSCM; 2005. h. 42-50.

6. Wheeler AP. Bernard GR. Treating patients with severe sepsis. N Engl J Med 1999;340:207-13.

7. Berstein WK, Khastgir T. The use and clinical importance of a substrate-specific electrode for rapid determination of blood lactate concentration. JAMA 1994;272:1678-84.

8. Rivers EP, Nguyen HB, Knoblich BP, Jacobsen G, Muzzin A, Ressler JA. Early lactate clearance is associated with improved outcome in severe sepsis and septic shock. Crit Care Med 2004;32:1637-42.

9. Vincent JL. Lactate and biochemical indexes of oxygenation. Dalam: Tobin MJ, penyunting. Principles and practice of intensive care monitoring. New York: McGraw-Hill Companies; 1998. h. 369-75.

10. Aduen J, Berstein W J, Berstein WK, Khastgir T, et al. The use and clinical importance of a substrate-specific elec-specific electrode for rapid determination of blood lactate consentration. JAMA 1994;272:1678-84.

11. Mendes AVA, Sapolnik R, Mendonca N. New guidelines for the clinical management of febrile neutropenia and sepsis in pediatric oncology patients. J Pediatr 2007;83(2 Suppl):S54-63. 